\title{
Genetic Confirmation of Mungbean (Vigna radiata) and Mashbean (Vigna mungo) Interspecific Recombinants using Molecular Markers
}

\author{
Ghulam Abbas ${ }^{1}$, Amjad Hameed ${ }^{2}$, Muhammad Rizwan ${ }^{*}$, Muhammad Ahsan ${ }^{3}$, \\ Muhammad J. Asghar ${ }^{1,4}$ and Nayyer lqbal ${ }^{5}$
}

${ }^{1}$ Plant Breeding and Genetics Division, Nuclear Institute for Agriculture and Biology, Faisalabad, Pakistan, ${ }^{2}$ Marker Assisted Breeding Group, Nuclear Institute for Agriculture and Biology, Faisalabad, Pakistan, ${ }^{3}$ Department of Plant Breeding and Genetics, University of Agriculture, Faisalabad, Faisalabad, Pakistan, ${ }^{4}$ Mungbean and Lentil Group, Nuclear Institute for Agriculture and Biology, Faisalabad, Pakistan, ${ }^{5}$ Pakistan Atomic Energy Commission, Islamabad, Pakistan

\section{OPEN ACCESS}

Edited by:

Sagadevan G. Mundree,

Queensland University of Technology,

Australia

Reviewed by:

Mohamed Suhail Rafudeen,

University of Cape Town, South Africa

Biswapriya Biswavas Misra,

University of Florida, USA

${ }^{*}$ Correspondence:

Muhammad Rizwan

rzi_rizwan@yahoo.com

Specialty section:

This article was submitted to

Plant Biotechnology,

a section of the journal

Frontiers in Plant Science

Received: 08 September 2015 Accepted: 23 November 2015 Published: 15 December 2015

Citation:

Abbas G, Hameed A, Rizwan M, Ahsan M, Asghar MJ and lqbal N (2015) Genetic Confirmation

of Mungbean (Vigna radiata) and Mashbean (Vigna mungo) Interspecific Recombinants using

Molecular Markers.

Front. Plant Sci. 6:1107. doi: 10.3389/fpls.2015.01107
Molecular confirmation of interspecific recombinants is essential to overcome the issues like self-pollination, environmental influence, and inadequacy of morphological characteristics during interspecific hybridization. The present study was conducted for genetic confirmation of mungbean (female) and mashbean (male) interspecific crosses using molecular markers. Initially, polymorphic random amplified polymorphic DNA (RAPD), universal rice primers (URP), and simple sequence repeats (SSR) markers differentiating parent genotypes were identified. Recombination in hybrids was confirmed using these polymorphic DNA markers. The NM $2006 \times$ Mash 88 was most successful interspecific cross. Most of true recombinants confirmed by molecular markers were from this cross combination. SSR markers were efficient in detecting genetic variability and recombination with reference to specific chromosomes and particular loci. SSR (RIS) and RAPD identified variability dispersed throughout the genome. In conclusion, DNA based marker assisted selection (MAS) efficiently confirmed the interspecific recombinants. The results provided evidence that MAS can enhance the authenticity of selection in mungbean improvement program.

Keywords: interspecific, recombination, hybridization, molecular markers, polymorphism

\section{INTRODUCTION}

Mungbean (Vigna radiata L. Wilzeck) known as green gram and mashbean (Vigna mungo L. Happer) as black gram are widely cultivated pulse crops belonging to family Fabaceae. In cereal based cropping system, these pulses are being consumed as supplemental crops. Mungbean which is more widely cultivated as compared to mashbean has some additional properties like having more easily digestible proteins and low proportions of flatulence factors (Gosal and Bajaj, 1983) but are deficient in some essential amino acids compared to blackgram (Poehlman, 1991). The present investigation was extended to interspecific hybridization of green gram and black gram in order to improve the level of essential amino acids in green gram.

Though interspecific cross of green gram, as female, to black gram has been reported successfully but the reciprocal cross was not found successful (Sen and Ghosh, 1960; Boling and Matlock, 1961; Chowdhury et al., 1977; Singh, 1981). Identification of interspecific hybrids is an important first 
TABLE 1 | Interspecific recombinant genotypes used for DNA Analysis.

\begin{tabular}{|c|c|c|c|c|c|}
\hline Sr.\# & Genotype & Parentage & Sr.\# & Genotype & Parentage \\
\hline 1 & MMH 11534 & Var.6601 × Mash 3-156-1 & 19 & MMH 9125 & Var.6601 × Mash 3-156-1 \\
\hline 2 & $\mathrm{MMH} 1125$ & NM-92 × Mash-97 & 20 & MMH 13115 & Var.6601 × Mash 3-156-1 \\
\hline 3 & MMH 4615 & NM-92 × Mash-97 & 21 & MMH 16111 & Var.6601 × Mash 3-156-1 \\
\hline 4 & MMH 53105 & NM-92 × Mash-97 & 22 & MMH 16425 & Var.6601 × Mash 3-156-1 \\
\hline 5 & MMH 5615 & NM-92 × Mash-97 & 23 & MMH 24425 & Var.6601 × Mash 3-156-1 \\
\hline 6 & MMH 2133 & NM $2006 \times$ Mash 88 & 24 & MMH 37414 & Var.6601 × Mash 3-156-1 \\
\hline 7 & MMH 2225 & NM $2006 \times$ Mash 88 & 25 & MMH 210115 & NM-92 × Mash-97 \\
\hline 8 & MMH 4255 & NM $2006 \times$ Mash 88 & 26 & MMH 3132 & NM-92 × Mash-97 \\
\hline 9 & MMH 7112 & Var.6601 × Mash 3-156-1 & 27 & MMH 4335 & NM-92 × Mash-97 \\
\hline 10 & MMH 1312 & NM-92 × Mash-97 & 28 & MMH 2131 & NM $2006 \times$ Mash 88 \\
\hline 11 & MMH 3563 & NM-92 × Mash-97 & 29 & MMH 2333 & NM $2006 \times$ Mash 88 \\
\hline 12 & MMH 3615 & NM-92 × Mash-97 & 30 & MMH 4211 & NM $2006 \times$ Mash 88 \\
\hline 13 & $\mathrm{MMH} 1115$ & NM $2006 \times$ Mash 88 & 31 & MMH 4224 & NM $2006 \times$ Mash 88 \\
\hline 14 & MMH 2112 & NM $2006 \times$ Mash 88 & 32 & MMH 6235 & NM $2006 \times$ Mash 88 \\
\hline 15 & $\mathrm{MMH} 2121$ & NM $2006 \times$ Mash 88 & 33 & MMH 7124 & NM $2006 \times$ Mash 88 \\
\hline 16 & MMH 4295 & NM $2006 \times$ Mash 88 & 34 & $\mathrm{MMH} 10212$ & Var.6601 × Mash 3-156-1 \\
\hline 17 & $\mathrm{MMH} 7111$ & NM $2006 \times$ Mash 88 & 35 & MMH 15135 & Var.6601 × Mash 3-156-1 \\
\hline 18 & MMH 7142 & NM $2006 \times$ Mash 88 & 36 & $\mathrm{MMH} 15334$ & Var.6601 × Mash 3-156-1 \\
\hline
\end{tabular}

step for self-pollinating crops as improper emasculation may result in selfed seeds. Moreover, in most cases the identification of interspecific hybrids on the basis of morphological characteristics can be difficult in field conditions due to epistasis and environmental influence. In field, $F_{1}$ hybrids can be identified on the basis of morphological characteristics only when one of the characteristic is intermediate between male and female parent or the plant shows high resemblance to male parent (Khajudparn et al., 2012). In certain cases, confirmation of true recombinants at the DNA level is required due to limitations of morphological characteristics alone.

TABLE 2 | Details of polymorphic RAPD, RIS, and SSR primers used for molecular confirmation of Mungbean $\times$ Mashbean interspecific recombinants.

\begin{tabular}{|c|c|c|c|}
\hline $\begin{array}{l}\text { Primer } \\
\text { Code }\end{array}$ & Sequence $\left(5^{\prime}-3^{\prime}\right)$ & $\begin{array}{l}\text { Annealing } \\
\text { temperature }\end{array}$ & $\begin{array}{l}\text { Product size } \\
\text { (bp) }\end{array}$ \\
\hline \multicolumn{4}{|c|}{ Random amplified polymorphic DNA (RAPD) } \\
\hline OPU-3 & CTATGCCGA & $35^{\circ} \mathrm{C}$ & $397-2060$ \\
\hline OPAJ-20 & ACACGTGGTC & $35^{\circ} \mathrm{C}$ & $440-1870$ \\
\hline OPS-07 & TCCGATGCTG & $35^{\circ} \mathrm{C}$ & 420-1940 \\
\hline \multicolumn{4}{|c|}{ SSR (RIS) primers } \\
\hline RIS-F & TAATTСТGCTTGCTCCATGC & $55^{\circ} \mathrm{C}$ & $604-2260$ \\
\hline RIS-R & ACTGGGGTGCACTGGATTAG & $55^{\circ} \mathrm{C}$ & $177-1828$ \\
\hline \multicolumn{4}{|c|}{ Simple sequence repeats (SSR) } \\
\hline VR040 & $\begin{array}{l}\text { (F) TGACAACATGGGAAGAAGAAGA } \\
\text { (R) ACACCAACACAAAAGCAAACAC }\end{array}$ & $52^{\circ} \mathrm{C}$ & $157-197$ \\
\hline VR062 & $\begin{array}{l}\text { (F) CGAAGACGAAATCTGAAGACAA } \\
\text { (R) TTACTTCTCCCAGCACTCCAAT }\end{array}$ & $52^{\circ} \mathrm{C}$ & $138-156$ \\
\hline VR0111 & $\begin{array}{l}\text { (F) TGCATCTTATTGAGTTCCGTG } \\
\text { (R) GTTTGGGGTGAATGTTGGATA }\end{array}$ & $55^{\circ} \mathrm{C}$ & 190-222 \\
\hline VR0304 & $\begin{array}{l}\text { (F) GAAGCGAAGAAGCCATAGAAAA } \\
\text { (R) CCTCACACACAACACAACAGAA }\end{array}$ & $52^{\circ} \mathrm{C}$ & $180-190$ \\
\hline
\end{tabular}

(F) Forward, (R) Reverse.
Molecular markers have been used for various purposes including determination of genetic relationships between individuals, construction of linkage maps, population genetics, phylogenetic studies, mapping of useful genes, and marker assisted selection/backcrosses. Several molecular marker systems, including randomly amplified polymorphic DNA (RAPD), universal rice primers (URP), simple sequence repeats (SSR), amplified fragment length polymorphism (AFLP), restriction fragment length polymorphism (RFLP), and inter-simple sequence repeats (ISSR) have been used in mungbean to characterize DNA variation patterns within and among closely related species (Dikshit et al., 2007; Raturi et al., 2012). DNA markers allow rapid identification of cultivars, hybrids, somaclonal variants, and clones with high efficiency and less labor cost (Reddy et al., 2002). In the present study, we successfully applied RAPD, URP, SSR, and SSR-RIS markers for molecular confirmation of 36 putative recombinants (Mungbean $\times$ Mashbean) that could not be discriminated from the self-pollinated progeny of the female parent on the basis of morphological characteristics.

\section{MATERIALS AND METHODS}

The present investigation was carried out at Plant Breeding and Genetics Division, Nuclear Institute for Agriculture and Biology, Faisalabad during the year, 2012-2013. The experimental material comprised of thirty six recombinant genotypes (Table 1) selected from field experiment along with three mungbean parents (Var.6601, NM-92, and NM2006) and three mashbean parents (Mash-97, Mash-88, and Mash 3-156-1). Recombinant genotypes were evaluated at molecular level to confirm the introgression of mashbean 


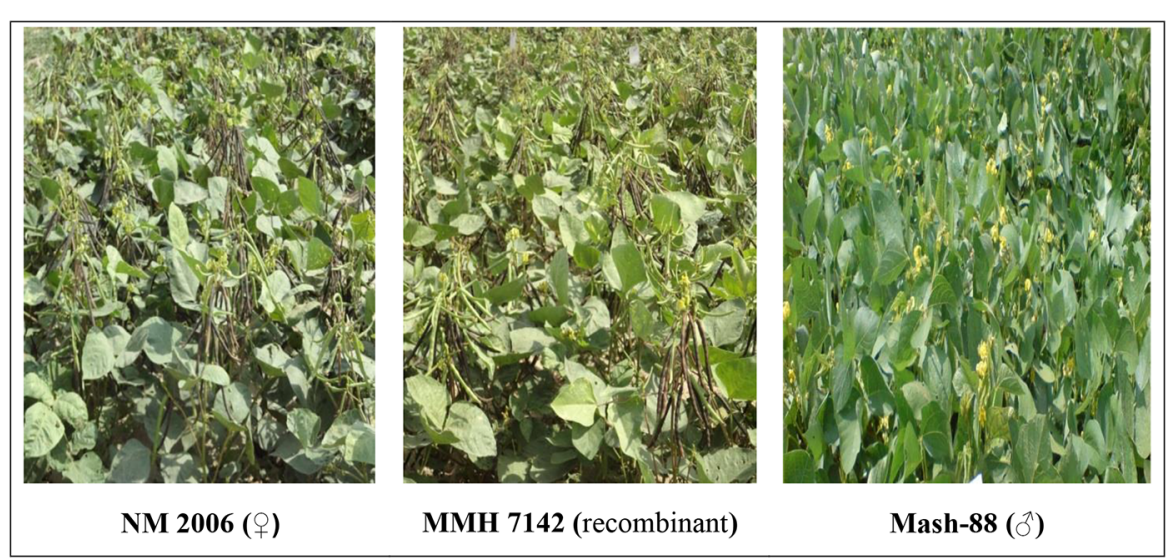

FIGURE 1 | Pictorial view of mungbean (female parent), mung $\times$ mash (recombinant) and mashbean (male parent).



FIGURE 2 | PCR profiles of parental genotypes using RIS-F (A) and RIS-R (B) marker.

genome into mungbean background. Seedlings of parental genotypes and recombinants were grown in petri plates at room temperature and young leaf tissues were used for extraction of DNA using the method described by Plaschke et al. (1995).
PCR was performed for RAPD (10), URP (12), and SSR (13) as described by Dikshit et al. (2007) and for SSR (RIS) (02) markers (Table 2). PCR mixtures were prepared containing $1 \mathrm{X}$ PCR buffer, $0.2 \mathrm{mM}$ dNTPs, $1.5 \mathrm{mM} \mathrm{MgCl}_{2}, 1 \mathrm{U}$ Taq polymerase (Enzynomics 2X TOPsimple ${ }^{\mathrm{TM}}$ DyeMIX-nTaq), $0.4 \mu \mathrm{M}$ primer, 


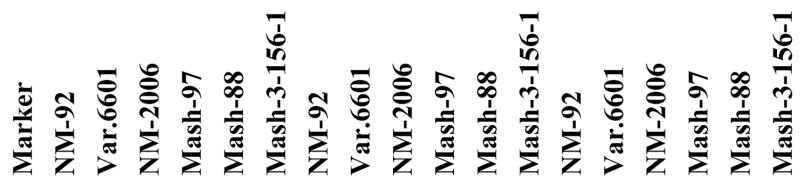

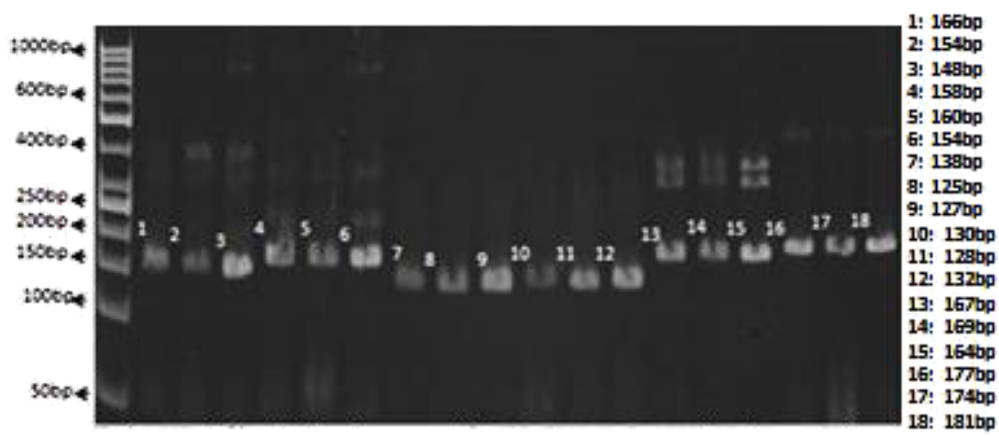

FIGURE 3 | PCR profiles of parental genotypes using SSR markers VR040 (L1-L6), VR062 (L7-L12) and VR0111 (L13-L18). *Marker for recombination.

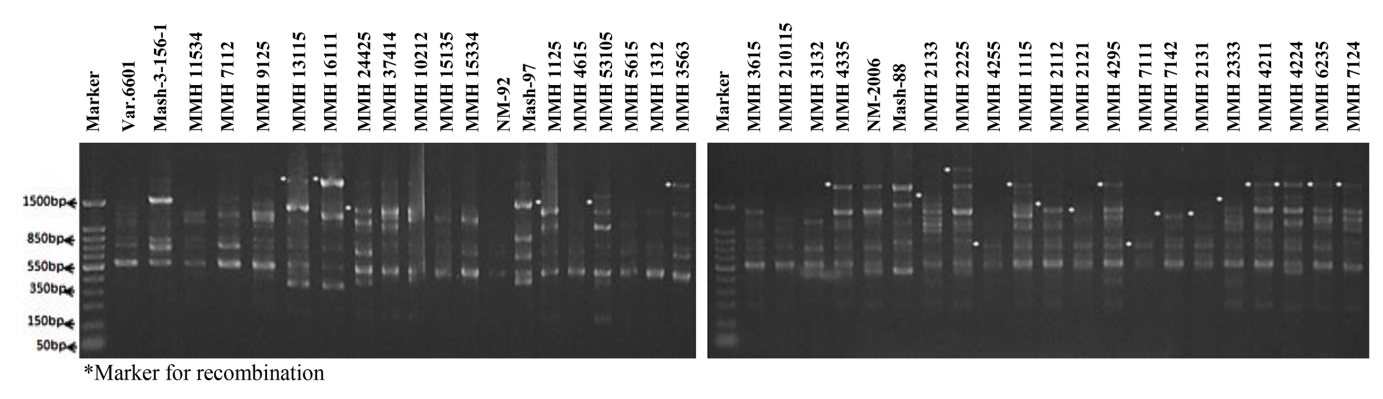

FIGURE 4 | PCR profiles of parental genotypes along with interspecific recombinants using RAPD primer OPU-3. *Marker for recombination.

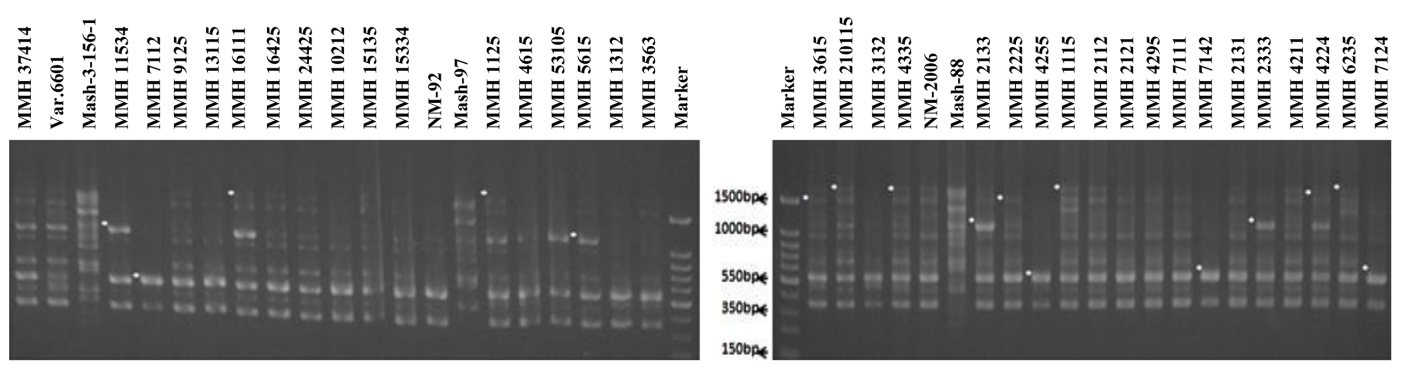

FIGURE 5 | PCR profiles of parental genotypes along with interspecific recombinants using RAPD primer OPAJ-20. *Marker for recombination.

and 100 ng template DNA. PCR amplifications for URP and SSR (RIS) markers were performed using thermal cycler (Bio RAD T100 , USA) with initial denaturation at $94^{\circ} \mathrm{C}$ for $3 \mathrm{~min}$ and then 40 cycles of denaturation at $94^{\circ} \mathrm{C}$ for $1 \mathrm{~min}$, primer annealing at $55^{\circ} \mathrm{C}$ for $1 \mathrm{~min}$, primer extension at $72^{\circ} \mathrm{C}$ for 2 min with a final extension step at $72^{\circ} \mathrm{C}$ for $10 \mathrm{~min}$. PCR amplifications for RAPD were performed with initial denaturation at $94^{\circ} \mathrm{C}$ for $4 \mathrm{~min}$ and then 40 cycles of denaturation at $94^{\circ} \mathrm{C}$ for $30 \mathrm{~s}$, primer annealing at $35^{\circ} \mathrm{C}$ for $1 \mathrm{~min}$, primer extension at $72^{\circ} \mathrm{C}$ for $2 \mathrm{~min}$ and final extension step at $72^{\circ} \mathrm{C}$ for $7 \mathrm{~min}$. PCR conditions used for SSR markers include initial denaturation at $94^{\circ} \mathrm{C}$ for $2 \mathrm{~min}$ and then 35 cycles of denaturation at $94^{\circ} \mathrm{C}$ for $30 \mathrm{~s}$, primer annealing at $50-60^{\circ} \mathrm{C}$ for $30 \mathrm{~s}$, primer extension at $72^{\circ} \mathrm{C}$ for $1 \mathrm{~min}$ and final extension step at $72^{\circ} \mathrm{C}$ for $10 \mathrm{~min}$.

The amplified products for URP, RAPD, and SSR (RIS) were separated electrophoretically on $1.5 \%$ agarose gel in $1 \times$ TBE buffer along with molecular weight markers (Bio Basic Inc. M109-A/M109-B and Thermo Scientific SM0373), stained with ethidium bromide and visualized and photographed over a UV trans illuminator (UVP Photo Doc-It ${ }^{\mathrm{TM}}$ Imaging System). The amplified products for SSR were separated 


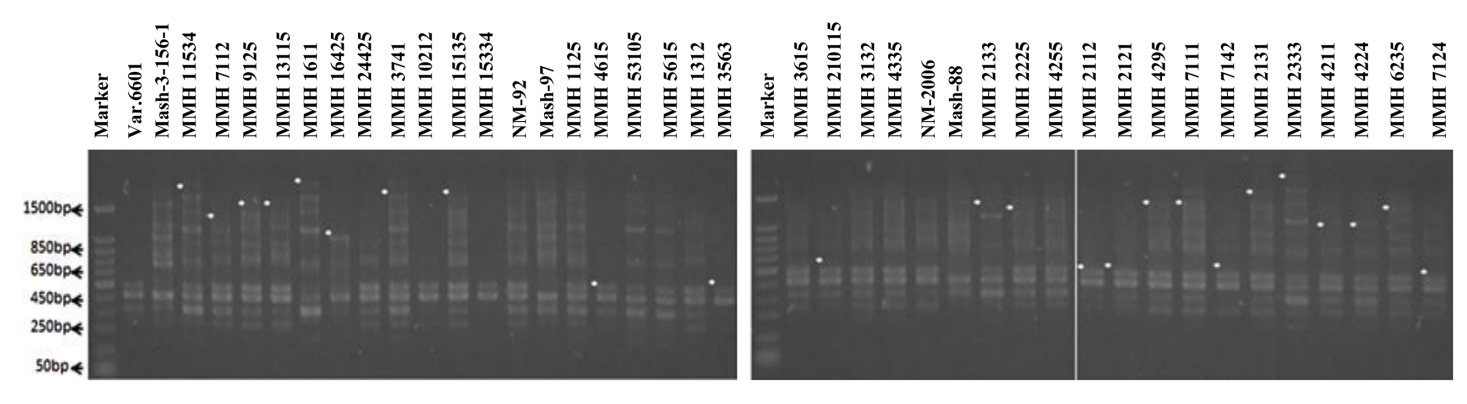

FIGURE 6 | PCR profiles of parental genotypes along with interspecific recombinants using RAPD primer OPS-07. *Marker for recombination.

electrophoretically (High throughput gel electrophoresis system, CBS Scientific) on $7 \%$ polyacrylamide gel, stained with ethidium bromide and visualized and photographed over a UV trans illuminator (UVP Photo Doc-It ${ }^{\mathrm{TM}}$ Imaging System). Banding patterns were analyzed by using UVI-BandMap software.

\section{RESULTS}

Mungbean $\times$ mashbean interspecific recombinants that showed morphological characteristics similar to their respective female parents were verified as true recombinants by using RAPD, URP, and SSR markers. One example of the similarity of recombinants morphological characteristics with the female parent is given in Figure 1. Firstly male and female parents of the recombinants were screened to identify the genetic variation present among parent genotypes and then the screening of interspecific recombinants was performed.

\section{Parental Screening}

Six parents (NM-92, Var.6601, NM-2006, Mash-97, Mash88, and Mash-3-156-1) involved in crossing were tested for genetic variation present at DNA level. PCR profiling using RIS-F clearly differentiated mungbean and mashbean parents from each other and also showed polymorphism within the male and female parent varieties (Figure 2A). RIS-F amplified band size of $1336 \mathrm{bp}$ for female parents and 1611 to $2254 \mathrm{bp}$ for male parents. Mashbean genotypes, used as male parents, exhibited male parent specific marker which interestingly, also produced polymorphic banding pattern for all the mashbean genotypes. At least two genotype specific markers were differentiated in different mashbean genotypes. RIS-R clearly differentiated mungbean and mashbean parents from each other (Figure 2B). RIS-R amplified band size of 488 and $1155 \mathrm{bp}$ for female parents (Mungbean) and 177, 958, and 1828 bp for male parent (Mashbean) genotypes involved in interspecific hybridization. The marker clearly differentiated not only mungbean and mashbean varieties from one another but intra varietal difference in mungbean and mashbean were also identified.

In case of SSR markers, out of 13 primers, only 3 (VR040, VR062, and VR0111) detected polymorphism between and among female and male parents. Thus, they proved to be an excellent resource for the identification of true recombinants (Figure 3). VR040 amplified bands of 148, 154, $166 \mathrm{bp}$ for female parents and 154, 158, 160 bp for male parents. VR062 amplified bands of 125, 127, $138 \mathrm{bp}$ for female parents and 128, 130, $132 \mathrm{bp}$ for male parents. Similarly, VR0111 amplified bands of 164, 167, $169 \mathrm{bp}$ for female parents and 174, 177, $181 \mathrm{bp}$ for male parents.

Molecular screening of parent genotypes was also performed along with interspecific recombinants through RAPD markers. Primer OPU-3 showed polymorphic results and clearly differentiated all parental cross combinations (Figure 4). In cross combination Var.6601 × Mash-3-156-1, female parent was clearly different from male parent. Similarly, polymorphic banding pattern was observed among other cross combinations which showed clear genetic differentiation between female and male parents. Primer OPU-3 also showed polymorphic banding patterns among female and male parent genotypes. Primer OPAJ20 successfully differentiated female and male parents (Figure 5) and also showed genetic variability among mungbean and mashbean genotypes. Due to its highly polymorphic nature, it can be used for genetic differentiation of interspecific recombinant genotypes from their parents. Another RAPD marker, OPS-7 showed clear differences between male and female parents of all cross combinations. It showed polymorphism among male and female parent genotypes (Figure 6) and proved to be efficient marker for screening true recombinants.

In general, all polymorphic RIS (RIS-F and RIS-R), SSR (VR040, VR062, and VR0111) and RAPD markers (OPU-3, OPAJ-20, and OPS-07) showed genetic differentiation not only between male and female genotypes of all cross combinations but also among mungbean (female parent) and mashbean (male parent) varieties/genotypes. These markers were found to be efficient for the identification of interspecific recombinants.

\section{Confirmation of Interspecific Recombinants}

PCR profile of parents and recombinants of Mungbean $\times$ Mashbean crosses by using RAPD marker OPU-3 is presented in Figure 4. OPU-3 showed polymorphic banding pattern when tested on recombinants along with their parents. This primer amplified different band sizes ranging from 397 to $2060 \mathrm{bp}$. OPU-3 confirmed 22 recombinants out of which 5 recombinants, i.e., $\mathrm{MMH}$ 4295, $\mathrm{MMH}$ 4211, $\mathrm{MMH}$ 
TABLE 3 | Confirmation of inter-specific Mung $\times$ Mash recombinant genotypes through RIS and RAPD analysis.

\begin{tabular}{|c|c|c|c|c|}
\hline \multirow{2}{*}{$\begin{array}{l}\text { Recombinant } \\
\text { Genotypes }\end{array}$} & \multicolumn{4}{|c|}{ Molecular markers } \\
\hline & RIS-F & $\begin{array}{l}\text { RAPD- } \\
\text { OPU-3 }\end{array}$ & $\begin{array}{l}\text { RAPD- } \\
\text { OPAJ-20 }\end{array}$ & $\begin{array}{l}\text { RAPD- } \\
\text { OPS-07 }\end{array}$ \\
\hline MMH 11534 & $R$ & - & $R$ & $\sigma^{x}$ \\
\hline MMH 1125 & $\sigma^{7}$ & $R$ & $0^{7}$ & - \\
\hline MMH 4615 & - & - & - & $\mathrm{R}$ \\
\hline MMH 53105 & $\mathrm{R}$ & $R$ & - & - \\
\hline MMH 5615 & $\mathrm{R}$ & - & $\mathrm{R}$ & - \\
\hline MMH 2133 & - & $\mathrm{R}$ & $\mathrm{R}$ & $\sigma^{x}$ \\
\hline MMH 2225 & $\sigma^{x}$ & $R$ & $0^{x}$ & $0^{x}$ \\
\hline MMH 4255 & $0^{x}$ & $\mathrm{R}$ & $\mathrm{R}$ & - \\
\hline MMH 7112 & $\mathrm{R}$ & - & $\mathrm{R}$ & $\sigma^{x}$ \\
\hline MMH 1312 & - & - & - & - \\
\hline MMH 3563 & - & $R$ & - & $\mathrm{R}$ \\
\hline MMH 3615 & - & - & $0^{7}$ & - \\
\hline MMH 1115 & $\sigma^{x}$ & $R$ & $\sigma^{x}$ & - \\
\hline MMH 2112 & $\sigma^{7}$ & $\mathrm{R}$ & - & $\mathrm{R}$ \\
\hline MMH 2121 & $\mathrm{R}$ & $\mathrm{R}$ & - & $\mathrm{R}$ \\
\hline MMH 4295 & $\sigma^{7}$ & $\sigma^{7}$ & - & $\sigma^{x}$ \\
\hline MMH 7111 & $\sigma^{7}$ & $R$ & - & $\sigma^{x}$ \\
\hline MMH 7142 & $\sigma^{7}$ & $R$ & $\mathrm{R}$ & $\mathrm{R}$ \\
\hline MMH 9125 & - & - & - & $\sigma^{x}$ \\
\hline MMH 13115 & - & $R$ & - & $\sigma^{7}$ \\
\hline MMH 16111 & $\sigma^{x}$ & $R$ & $\mathrm{R}$ & $\sigma^{7}$ \\
\hline MMH 16425 & $0^{7}$ & - & - & $\mathrm{R}$ \\
\hline MMH 24425 & - & $\mathrm{R}$ & - & - \\
\hline MMH 37414 & - & - & - & $\sigma^{\pi}$ \\
\hline MMH 210115 & $0^{7}$ & - & $\sigma^{7}$ & $\mathrm{R}$ \\
\hline MMH 3132 & - & - & - & - \\
\hline MMH 4335 & - & $R$ & $\sigma^{x}$ & - \\
\hline MMH 2131 & - & $\mathrm{R}$ & - & $\sigma^{7}$ \\
\hline MMH 2333 & $\sigma^{x}$ & $R$ & $\mathrm{R}$ & $\sigma^{x}$ \\
\hline MMH 4211 & $\sigma^{7}$ & $\sigma^{7}$ & - & $\sigma^{7}$ \\
\hline MMH 4224 & $\sigma^{7}$ & $\sigma^{7}$ & $\mathrm{R}$ & $\sigma^{7}$ \\
\hline MMH 6235 & $\sigma^{x}$ & $\sigma^{7}$ & $0^{7}$ & $\sigma^{7}$ \\
\hline МMH 7124 & $\sigma^{7}$ & $\sigma^{7}$ & $\mathrm{R}$ & $\sigma^{7}$ \\
\hline MMH 10212 & $\mathrm{R}$ & - & - & - \\
\hline MMH 15135 & - & - & - & $\sigma^{x}$ \\
\hline MMH 15334 & $\mathrm{R}$ & - & - & - \\
\hline
\end{tabular}

$\sigma^{\top}$, Male-specific band; -, Not confirmed; R, Recombinant.

4224, MMH 6235, and MMH 7124 showed clear male parent specific band. While remaining 17 recombinants were confirmed through diversified PCR profiles that were different from male and female parent (Table 3). Another RAPD primer OPAJ-20 which found to be polymorphic in parental screening and showed clear genetic differentiation between male and female parents as well as among male and female parent genotypes was used to confirm interspecific recombinants. OPAJ-20 produced multiple bands ranging from 440 to $1870 \mathrm{bp}$ (Figure 5) and confirmed 17 interspecific recombinants (Table 3). Out of these 17 recombinants, 6 (MMH 2225, MMH 3615, MMH 1115, MMH 210115, MMH 4335, and MMH 6235) were confirmed through male parent specific bands. The remaining 11 recombinants were confirmed through diversified PCR profiles as compared to respective parents.

Among RAPDs, OPS-07 confirmed maximum number of recombinants with band sizes ranging from 420 to $1940 \mathrm{bp}$. This primer showed clear genetic differences between female and male parent genotypes. It also showed polymorphism among mungbean (female parent) and mash bean (male parent) genotypes (Figure 6). A total of 24 genotypes out of 36 were confirmed as recombinant genotypes (Table 3 ). Clear male parent specific markers were detected in 17 recombinants by using this primer.

Among SSR (RIS) primers, the polymorphic banding pattern of RIS-F when tested on different recombinants along with their parents (Figure 7) confirmed 23 out of 36 recombinants. Clear male parent specific bands were detected in 16 recombinants by using this marker. Moreover, some recombinants were confirmed through diversified PCR profiles as compared to male and female parent (Table 3). This primer amplified different band sizes ranging from 604 to $2260 \mathrm{bp}$.

Simple sequence repeat markers further confirmed recombinations in recombinants selected from RAPD and RIS analysis. For this purpose a total of 13 SSR markers were used and only four were found polymorphic, whereas others showed monomorphic banding patterns. VR040 was one of the SSR markers which clearly differentiated male and female parent genotypes and showed polymorphic banding patterns in recombinants analyzed in this study. Distinct male parent specific markers were detected by using this primer (Figure 8). This primer amplified band sizes of $157 \mathrm{bp}$ for female parent and $170 \mathrm{bp}$ for male parent in NM$2006 \times$ Mash-88 cross combination and amplified a band of $170 \mathrm{bp}$ in recombinants. VR040 amplified band sizes of 157 and $175 \mathrm{bp}$ for female and male parents respectively for NM-92 $\times$ Mash-97 cross combination. For Var.6601 $\times$ Mash3-156-1 it produced band size of 190 bp for female parent and $197 \mathrm{bp}$ for male parent. VR040 showed male specific bands in 21 out of 26 recombinants. The remaining five recombinants $(\mathrm{MMH}$ 7124, MMH 1125, MMH 1611, MMH 16425, and MMH 11534) showed female specific marker, hence not confirmed as true recombinants by using this primer (Table 4). Another SSR marker, VR062 which showed polymorphic banding pattern in parental genotypes also revealed clear differentiation in recombinants in comparison with their respective female and male parent genotypes. Band sizes of male specific amplification products, i.e., 144, 148 , and 156 bp were found in NM-2006 $\times$ Mash-88, NM$92 \times$ Mash-97, and Var.6601 × Mash-3-156-1 recombinants, respectively. This primer declared 17 recombinants true recombinants since they showed male parent specific banding pattern (Table 4). The remaining nine recombinants were not confirmed by this marker as they showed their respective female parent specific banding pattern. Many of the recombinants identified by VR062 were also indicated as true recombinants by VR040. The PCR profiles of recombinants along with their parents amplified by VR062 are presented in Figure 9. 


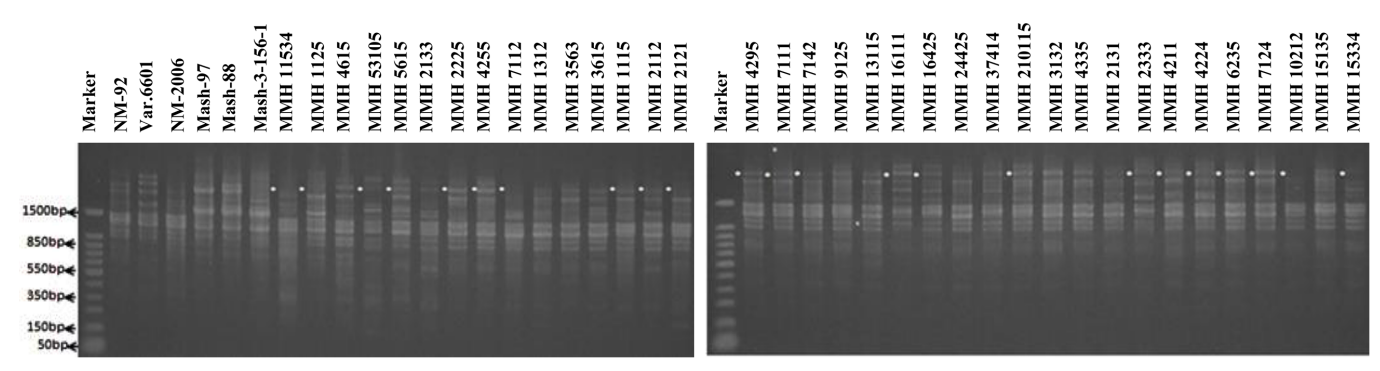

FIGURE 7 | PCR profiles of parental genotypes along with interspecific recombinants using RIS-F. * Marker for recombination.

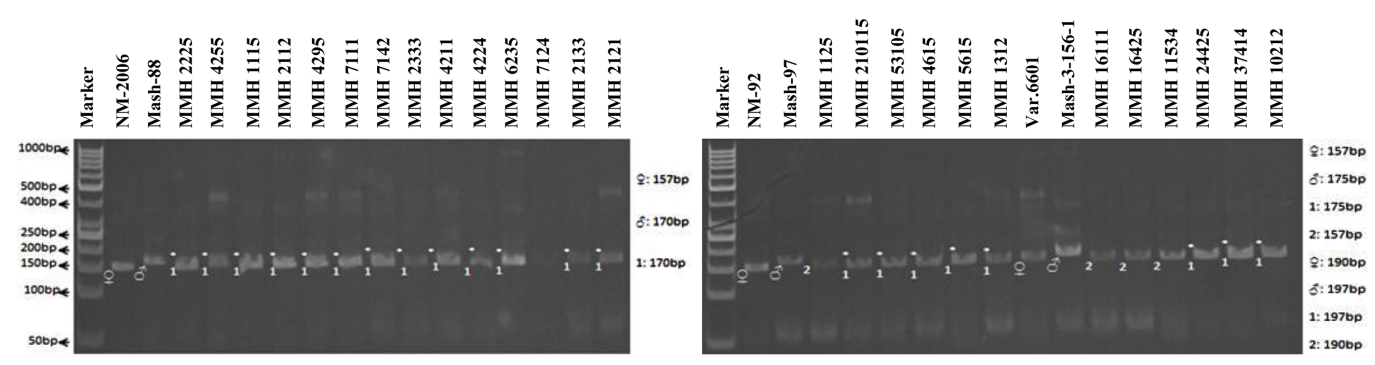

FIGURE 8 | PCR profiles of parental genotypes along with interspecific recombinants using SSR marker VR040. *Marker for recombination.

Simple sequence repeat marker VR0111 was efficient in detecting genetic variability between female and male parent genotypes. In female parent genotypes, this primer amplified band sizes of 190 bp in NM-2006 and NM-92 and 211 bp in Var.6601 whereas in male parent genotypes it amplified $198 \mathrm{bp}$ in Mash-88, 208 bp in Mash-97, and 222 bp in Mash-3-1561. This primer amplified male specific band sizes of 198, 208, and $222 \mathrm{bp}$ in the recombinants (Figure 10). This was the only primer which showed complete male parent specific banding pattern thus declaring maximum number of recombinants as true recombinants (Table 4). Distinct genetic differentiation of parental genotypes was also revealed by SSR marker VR0304. This primer amplified band sizes of 180 (NM-2006), 181 (NM92), 186 bp (Var.6601) in female parents and 181 (Mash-3-156-1), 186 (Mash-97), 190 bp (Mash-88) in male parents while male specific band sizes of 181, 186, and $190 \mathrm{bp}$ in recombinants. The PCR profiles of recombinants along with their respective female and male parent genotypes (Figure 11) confirmed 18 recombinants out of 26 genotypes (Table 4). $\mathrm{MMH} 2333, \mathrm{MMH}$ 4224, MMH 7124, MMH 2133, МMH 2121, МMH 24425, MMH 37414, and MMH 10212 showed female specific marker, hence not confirmed as true recombinants by using this primer. VR040 also did not confirmed MMH 7124 as recombinants. The recombinants, MMH 2333, MMH 2133, and MMH 2121 were also not confirmed by VR 062 .

\section{DISCUSSION}

Our investigation showed RAPD, URP, and SSR markers to be efficient tools in discriminating the interspecific recombinants from the self-pollinated progeny of female parents. These
TABLE 4 | Re-confirmation of inter-specific Mung $\times$ Mash recombinant genotypes through SSR analysis.

\begin{tabular}{|c|c|c|c|c|}
\hline \multirow[t]{2}{*}{ Recombinant Genotypes } & \multicolumn{4}{|c|}{ SSR markers } \\
\hline & VR040 & VR062 & VR0111 & VR0304 \\
\hline MMH 16425 & - & $\mathrm{R}$ & $\mathrm{R}$ & $\mathrm{R}$ \\
\hline MMH 2112 & $\mathrm{R}$ & $\mathrm{R}$ & $\mathrm{R}$ & $\mathrm{R}$ \\
\hline MMH 16111 & - & - & $\mathrm{R}$ & $\mathrm{R}$ \\
\hline MMH 7111 & $\mathrm{R}$ & $\mathrm{R}$ & $\mathrm{R}$ & $\mathrm{R}$ \\
\hline MMH 7142 & $\mathrm{R}$ & $\mathrm{R}$ & $\mathrm{R}$ & $\mathrm{R}$ \\
\hline MMH 6235 & $\mathrm{R}$ & - & $\mathrm{R}$ & $\mathrm{R}$ \\
\hline MMH 4255 & $\mathrm{R}$ & - & $\mathrm{R}$ & $\mathrm{R}$ \\
\hline MMH 1115 & $\mathrm{R}$ & $\mathrm{R}$ & $\mathrm{R}$ & $\mathrm{R}$ \\
\hline MMH 4295 & $\mathrm{R}$ & - & $\mathrm{R}$ & $\mathrm{R}$ \\
\hline MMH 4224 & $\mathrm{R}$ & $\mathrm{R}$ & $\mathrm{R}$ & - \\
\hline MMH 7124 & - & $\mathrm{R}$ & $\mathrm{R}$ & - \\
\hline MMH 2333 & $\mathrm{R}$ & - & $\mathrm{R}$ & - \\
\hline MMH 1125 & - & - & $\mathrm{R}$ & $\mathrm{R}$ \\
\hline MMH 4211 & $\mathrm{R}$ & $\mathrm{R}$ & $\mathrm{R}$ & $\mathrm{R}$ \\
\hline MMH 2225 & $\mathrm{R}$ & $\mathrm{R}$ & $\mathrm{R}$ & $\mathrm{R}$ \\
\hline MMH 210115 & $\mathrm{R}$ & - & $\mathrm{R}$ & $\mathrm{R}$ \\
\hline
\end{tabular}

-, Not confirmed; R, Recombinant.

markers can be effectively used to fingerprint and differentiate plants with highly similar morphological characteristics. The recombination status of hybrids can be confirmed by comparing the amplified polymorphic bands between recombinants and female parents (male parent specific bands). RAPD (OPU3, OPAJ-20, and OPS-07) depicted polymorphism between male and female parents and among recombinants. Many other studies reported that RAPD markers are efficient in 


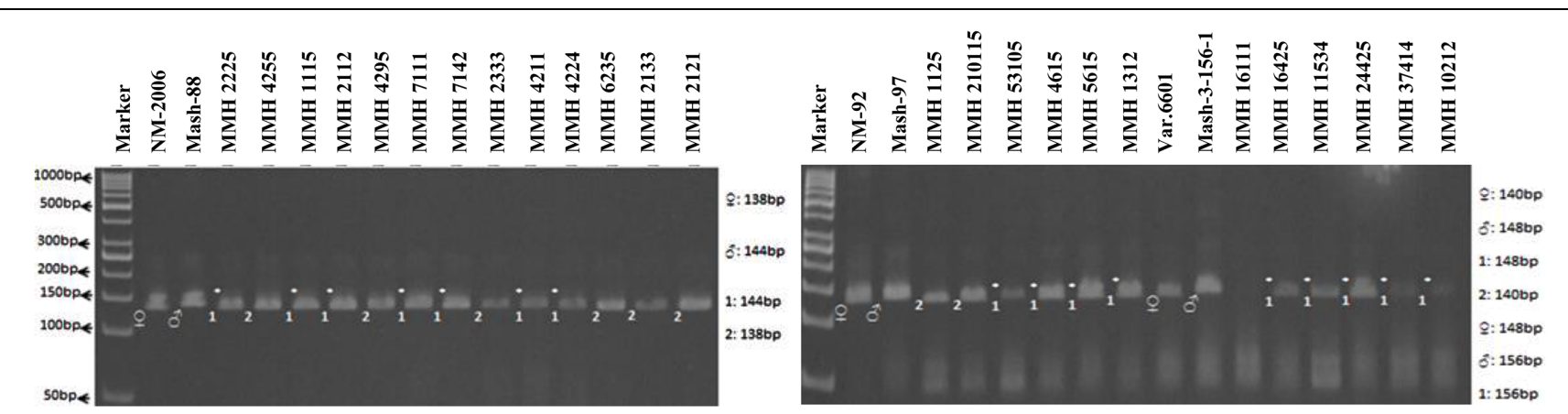

FIGURE 9 | PCR profiles of parental genotypes along with interspecific recombinants using SSR marker VR062. *Marker for recombination.

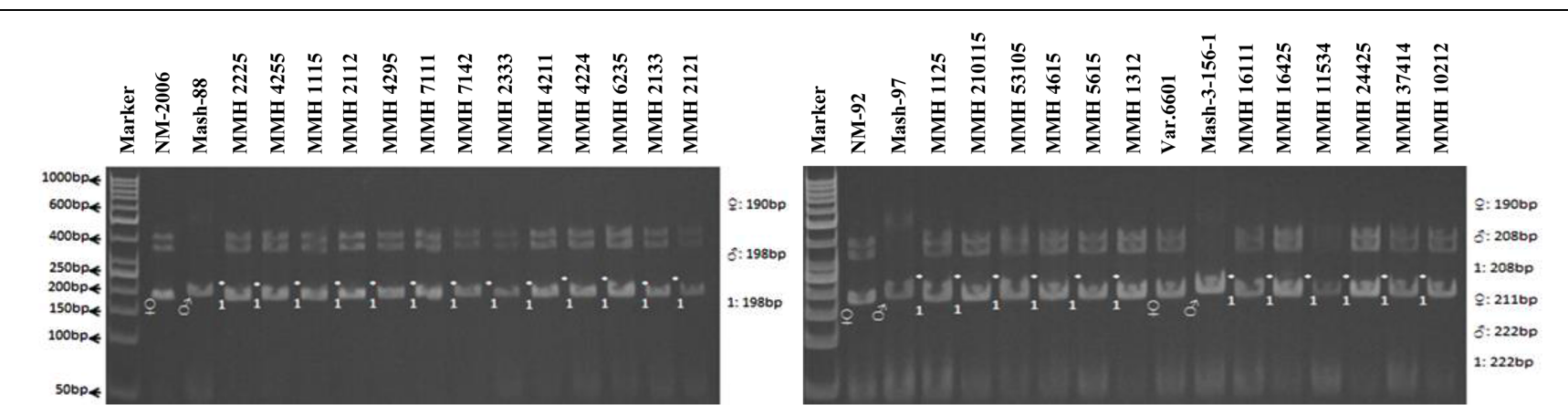

FIGURE 10 | PCR profiles of parental genotypes along with interspecific recombinants using SSR marker VR0111. *Marker for recombination.

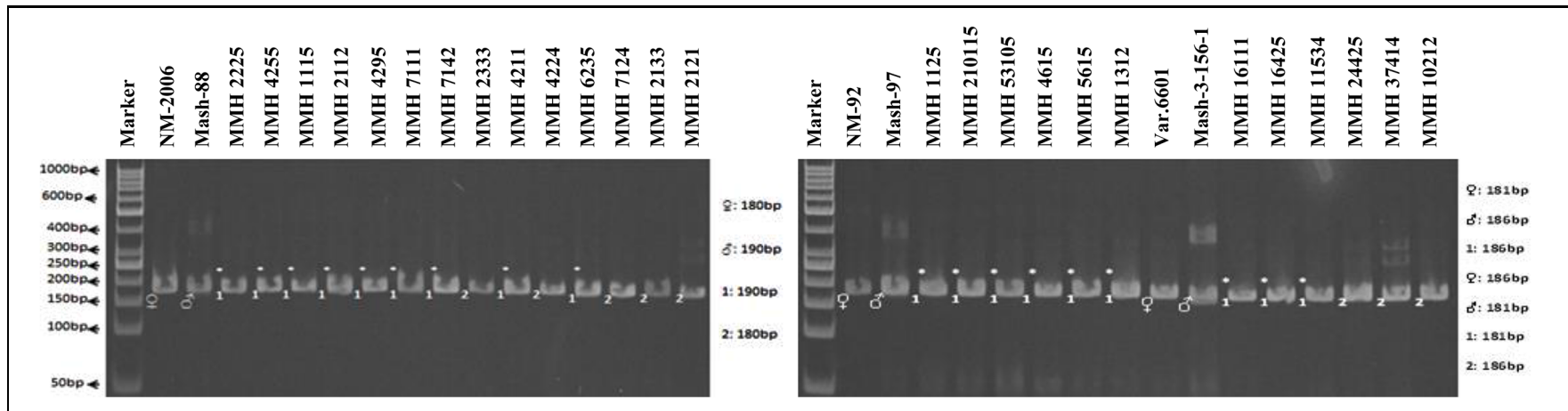

FIGURE 11 | PCR profiles of parental genotypes along with interspecific recombinants using SSR marker VR0304. * Marker for recombination.

amplifying DNA from dispersed polymorphic loci from the genome (Baral and Bosland, 2002; Rasul et al., 2007; Wang et al., 2011). These markers can be used to assess genetic variability among and between Vigna species (Kaga et al., 1996; Santalla et al., 1998; Lakhanpaul et al., 2000; Ba et al., 2004; Saini et al., 2004; Raturi et al., 2012). Wang et al. (2008) reported thirty gene derived markers which were employed to reveal interspecific phylogenetic relationships and genetic diversity among 48 accessions of 12 Vigna species. Elham et al. (2010) used RAPD markers for determining genetic relationship among Vigna species. Souframanien and Gopalakrishna (2004) studied the DNA polymorphism in 18 elite blackgram genotypes by using RAPD and ISSR markers. Amplification of genomic
DNA of blackgram genotypes, using RAPD analysis, yielded 44 polymorphic fragments varied in size from 200 bp (OPA-13) to 2500 bp (OPK-4). Similarly, Srivastava et al. (2011) used RAPD markers for genetic diversity analysis of blackgram genotypes. Total amplified fragments were 346 out of which 338 were polymorphic $(97.68 \%)$ with fragment size varied from 50 to 3000 bp.

Similarly, 12 URP markers were used out of which some markers did not show any amplification and some showed very little or no polymorphism. After testing RAPD and URP markers, the recombinants were screened with 2 SSR (RIS) primers and both primers showed polymorphic banding pattern. RIS primers separately and at lower annealing temperature amplified products 
in mung $\times$ mash recombinants and may be used as potential markers. Thereafter, 13 SSR markers were used out of which only four markers, VR040, VR062, VR0111, and VR0304 exhibited polymorphism. Dikshit et al. (2007) also used URP, RAPD, and SSR markers for genetic differentiation of Vigna species and concluded that SSR marker system was more efficient in detecting genetic variability among all the Vigna species. Dikshit et al. (2012) used 78 SSR's, 41 were amplified in one Vigna species and out of this 36 were observed to be polymorphic. Kajonphol et al. (2012), found 21 SSR markers to be common between mashbean and mungbean. Gupta and Varshney (2000) and Hernandez et al. (2002) used SSR markers very effectively in marker assisted selection, genotyping, and gene mapping. Chen et al. (2015) identified EST-SSR markers through transcriptome sequencing of mungbean genes. Out of 200 randomly selected SSR loci, 66 primer pairs produced reproducible amplicons that were polymorphic among 31 mungbean accessions. Wang et al. (2015) carried out SSR analysis of mungbean based on an SSR enriched library and reported 387 validated and mapped markers that can be used in marker assisted selection in mungbean.

\section{CONCLUSION}

All the three maker systems used showed polymorphism between mashbean (male) and mungbean (female) and among male

\section{REFERENCES}

Ba, F., Pasquet, R. S., and Gepts, P. (2004). Genetic diversity in cowpea [Vigna unguiculata (L.) Walp.] as revealed by RAPD markers. Genet. Resour. Crop Evol. 51, 539-550. doi: 10.1023/B:GRES.0000024158.83190.4e

Baral, J., and Bosland, P. W. (2002). Genetic diversity of a Capsicum germplasm collection from Nepal as determined by randomly amplified polymorphic DNA markers. J. Am. Soc. Hortic. Sci. 127, 316-324.

Boling, M., and Matlock, R. S. (1961). Mungbean hybridization technique. Agron. J. 53, 54. doi: 10.2134/agronj1961.000219620053000 10020x

Chen, H., Wang, L., Wang, S., Liu, C., Blair, M. W., and Cheng, X. (2015). Transcriptome sequencing of mungbean (Vigna radiata L.) genes and the identification of EST-SSR markers. PLOS ONE 10:e0120273. doi: 10.1371/journal.pone. 0120273

Chowdhury, R. K., Chowdhury, J. B., and Singh, V. P. (1977). An amphidiploid between Vigna radiata var. radiata and Vigna mungo. Crop. Improv. 4, 113-114.

Dikshit, H. K., Jhang, T., Singh, N. K., Koundal, K. R., Bansal, K. C., Chandra, N., et al. (2007). Genetic differentiation of Vigna species by RAPD, URP and SSR markers. Biol. Plant. 51, 451-457. doi: 10.1007/s10535-007-0095-8

Dikshit, H. K., Singh, D., and Singh, A. (2012). Utility of Adzuki bean (Vigna angularis (Wild) Ohwi and Ohashi) Simple Sequence Repeats (SSR) marker in genetic analysis of mungbean and related Vigna spp. Afr. J. Biotechnol. 11, 13261-13268.

Elham, A. A. A., Atef, A. A. H., Nagwa, R. A., Abd El-Rahman, M. F. A., and Ahmed, Y. M. (2010). Assessment of genetic variations in some vigna species by RAPD and ISSR analysis. New York Sci. J. 3, 120-128.

Gosal, S. S., and Bajaj, Y. P. S. (1983). Interspecific hybridization between Vigna mungo and Vigna radiata through embryo culture. Euphytica 32, 129-137. doi: 10.1007/BF00036873

Gupta, P. K., and Varshney, R. (2000). The development and use of microsatellite markers for genetic analysis and plant breeding with emphasis on bread wheat. Euphytica 113, 163-185. doi: 10.1023/A:1003910819967

Hernandez, P., Lauri, D. A., Martin, A., and Snape, J. W. (2002). Utility of barley and wheat Simple Sequence Repeat (SSR) markers for genetic analysis and female parent genotypes except URP. They revealed the presence of genetic variation in the investigated material that can be exploited for an efficient breeding program. Among various crosses, NM $2006 \times$ Mash 88 was found to be the most successful interspecific cross as highest proportion of the genetically confirmed recombinants belonged to this cross combination. Comparison of marker systems confirmed the SSR efficiency in discerning genetic variability and recombination with reference to specific chromosome number and loci. RIS and RAPD were found to be more efficient in amplifying DNA from dispersed polymorphic loci from the genome and may be used for recombinant identification where SSR fails to detect polymorphism. In conclusion, marker assisted selection approach is helpful in selecting true interspecific recombinants among Mungbean $\times$ Mashbean. This approach can differentiate the interspecific recombinant seed from self-pollinated seed; thus can overcome the issues related to environment and inadequacy of morphological characteristics alone.

\section{AUTHOR CONTRIBUTIONS}

GA, NI, AH, MJA and MA were involved in planning of the study. $\mathrm{MR}$ and $\mathrm{AH}$ were involved in execution of practical lab work and data analysis. AH, MR, GA and NI contributed in manuscript writing and finalization of draft.

of Hordeum chilense and titrodeum. Theor. Appl. Genet. 104, 735-739. doi: 10.1007/s001220100674

Kaga, A. N., Tomooka, N., Egawa, Y., Hosaka, K., and Kamijima, O. (1996). Species relationships in subgenus ceratotropis (Genus Vigna) as revealed by RAPD analysis. Euphytica 88, 17-24. doi: 10.1007/BF00029261

Kajonphol, T., Sangsiri, C., Somta, P., Toojinda, T., and Srinives, P. (2012). SSR Map construction and quantitative traits loci (QTL) identification of major agronomic traits in Mungbean (Vigna radiata (L.) Wilczek). SABRAO J. Breed. Genet. 44, 71-86.

Khajudparn, P., Prajongjai, T., Poolsawat, O., and Tantasawat, P. A. (2012). Application of ISSR markers for verification of F1 hybrids in mungbean (Vigna radiata). Genet. Mol. Res. 11, 3329-3338. doi: 10.4238/2012.September.17.3

Lakhanpaul, S., Chadha, S., and Bhat, K. V. (2000). Random amplified polymorphic DNA (RAPD) analysis in Indian mungbean (Vigna radiata (L.) Wilczek) cultivars. Genetica 3, 227-234. doi: 10.1023/A:1017511 918528

Plaschke, J., Ganal, M. W., and Roder, M. S. (1995). Detection of genetic diversity in closely related bread wheat using microsatellite markers. Theor. Appl. Genet. 91, 1001-1007. doi: 10.1007/BF00223912

Poehlman, J. M. (1991). The Mungbean. New Delhi: Oxford and IBH publishing Company, 1-343.

Rasul, M. G., Hirammatsu, M., and Okubo, H. (2007). Genetic relatedness (diversity) and cultivar identification by randomly amplified polymorphic DNA (RAPD) markers in teasle gourd (Momordica dioica Roxb.). Sci. Hortic. 111, 271-279. doi: 10.1016/j.scienta.2006.10.023

Raturi, A., Singh, S. K., Sharma, V., and Pathak, R. (2012). Molecular characterization of Vigna radiata (L.) Wilczek genotypes based on nuclear ribosomal DNA and RAPD polymorphism. Mol. Biol. Rep. 39, 2455-2465. doi: 10.1007/s11033-011-0996-7

Reddy, M. P., Sarla, N., and Siddiq, E. A. (2002). Inter simple sequence repeat (ISSR) polymorphism and its application in plant breeding. Euphytica 128, 9-17. doi: 10.1023/A:1020691618797

Saini, A., Reddy, K. S., and Jawali, N. (2004). Evaluation of long primers for APPCR analysis of mungbean [Vigna radiata (L.) Wilczek]: genetic relationship and fingerprinting of some genotypes. Indian J. Biotechnol. 3, 511-518. 
Santalla, M., Power, J. B., and Davey, M. R. (1998). Genetic diversity in mungbean germplasm revealed by RAPD markers. Plant Breed. 117, 473-478. doi: 10.1007/s11033-011-0996-7

Sen, N. K., and Ghosh, A. K. (1960). Interspecific hybridization between P. aureus and P. mungo. Bull. Bot. Sot. Bengal 14, 1-4.

Singh, D. P. (1981). Breeding for resistance to diseases in greengram and blackgram. Theor. Appl. Genet. 59, 1-10. doi: 10.1007/BF00275766

Souframanien, J., and Gopalakrishna, T. (2004). A comparative analysis of genetic diversity in blackgram genotypes using RAPD and ISSR markers. Theor. Appl. Genet. 109, 1683-1693. doi: 10.1007/s00122-004-1797-3

Srivastava, P., Pandey, A., and Sinha, D. P. (2011). Genetic diversity analysis in different varieties of black gram using RAPD markers. J. Plant Breed. Crop Sci. 3, 53-59.

Wang, L. X., Elbaidouri, M., Abernathy, B., Chen, H. L., Wang, S. H., Lee, S. H., et al. (2015). Distribution and analysis of SSR in mungbean (Vigna radiata L.) genome based on an SSR-enriched library. Mol. Breed. 35, 1-10. doi: 10.1007/s11032-015-0259-8

Wang, M. L., Barkley, N. A., Gillaspie, G. A., and Pederson, G. A. (2008). Phylogenetic relationships and genetic diversity of the USDA
Vigna germplasm collection revealed by gene-derived markers and sequencing. Genet. Res. 90, 467-480. doi: 10.1017/S00166723080 09889

Wang, P., Lu, Y., Zheng, M., Rong, T., and Jawali, N. (2011). RAPD and internal transcribed spacer sequence analyses reveal Zea nicaraguensis as a section luxuriantes species close to Zea luxurians. PLoS ONE 6:e16728. doi: 10.1371/journal.pone.0016728

Conflict of Interest Statement: The authors declare that the research was conducted in the absence of any commercial or financial relationships that could be construed as a potential conflict of interest.

Copyright (C) 2015 Abbas, Hameed, Rizwan, Ahsan, Asghar and Iqbal. This is an open-access article distributed under the terms of the Creative Commons Attribution License (CC BY). The use, distribution or reproduction in other forums is permitted, provided the original author(s) or licensor are credited and that the original publication in this journal is cited, in accordance with accepted academic practice. No use, distribution or reproduction is permitted which does not comply with these terms. 